\title{
IDÉIAS
}

\section{O Ombudsman Sueco: Um \\ Vigilante Real}

$\mathrm{Na}$ Suécia, prisioneiros que estão insatisfeitos com as condições das prisōes, estudantes que querem reclamar dos professores, contribuintes desgostosos com o excesso de impostos que têm que pagar, enfim, todos os que têm qualquer queixa a fazer encontram na figura do Ombudsman da Justiça o ombro amigo e o ouvido atento a todas as horas.

E mesmo para um paraiso social como a Suécia é considerada, queixa é o que não falta. Nos primeiros cem anos de existência - O Ombudsman é uma instituição que existe desde 1809 oficialmente chegaram 70 queixas por ano. Depois, este número cresceu para 50 e atualmente, o número de reclamações chega à média de 3.500 por ano.

Em recente conferência pronunciada na Fundação Centro de Formação do Servidor Público - FUNCEP - o Ombudsman da Suécia, Anders Wigelius, mostrou como é que em seu pais, as queixas são recebidas e quais as providências que são tomadas.

\section{História}

O cargo de Ombudsman da Justiça (Justitieombudsman) foi criado em 1809. Ele já possuía, no entanto, uma contrapartida mais remota. Quando o Rei Carlos XII da Suécia foi derrotado na Batalha de Poltava na Rússia (1709), teve de refugiar-se na Turquia, onde permaneceu por muitos anos. Entrementes, o mal-estar e a desordem predominavam na Suécia. A fim de deter esse processo, em 1713, o Rei, que se encontrava então em Timurtasch, na Turquia, ordenou que fosse criado um cargo na Suécia a ser chefiado pelo Ombudsman de mais elevado posto do reino. A tarefa desse Ombudsman seria assegurar que as leis e os estatutos fossem seguidos e que os funcionários públicos seguissem suas obrigações. Esse cargo, conhecido posteriormente como o de Chan-

Anders Wigelius é o Ombudsman da Justiça do governo sueco.
Anders Wigelius

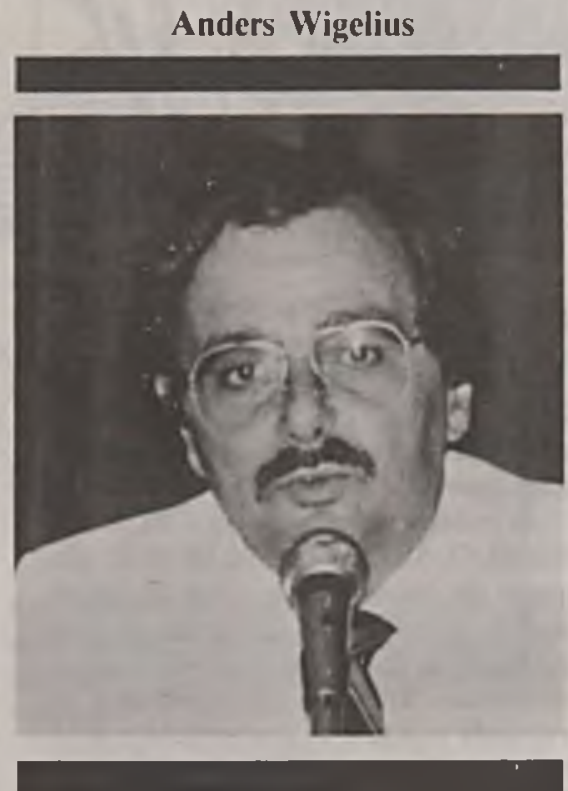

celer da Justiça (Justitiekansler), ainda existe.

De 1766 a 1772 o Parlamento, que assumira praticamente todo o poder do Rei, exerceu o direito de apontar o Chanceler da Justiça. Em 1772, no entanto, o Rei Gustavo III recuperou as prerrogativas reais, incluindo essa designação.

Em 1809, o Rei Gustavo IV Adolf, que reinara como um déspota absoluto, foi destronado. O Parlamento foi convocado pela primeira vez durante muitos anos e decidiu adotar uma nova Constituição, baseada no principio de um equilíbrio de poder entre o Rei e o Parlamento. A Constituição continha cláusulas para a nomeação, pelo Rei, do Chanceler da Justiça e para a eleição, pelo Parlamento, de um Ombudsman da Justiça. Este deveria ser "um homem de renomada capacidade em assuntos jurídicos e integridade inabalável". Sua tarefa consistia em supervisionar, como um representante do Parlamento, o cumprimento das leis e estatutos por todos os funcionários do Governo.

O primeiro Ombudsman (Barão L. A. Mannerheim) foi eleito em 1810. Ele tinha sido presidente do comitê parlamentar que redigiu a Constituição de 1809 e foi considerado o líder do "Partido Cons- titucional", então no poder. Essa foi a única ocasião em que um Ombudsman foi eleito exclusivamente por razões políticas. Ele foi o único Ombudsmen parlamentar no posto e supervisionou todas as autoridades, civis e militares.

Em 1915, o Parlamento julgou necessário desvincular a função de supervisão das autoridades militares das funções gerais de supervisão do Ombudsman da Justiça e criou um cargo à parte para o controle das forças armadas - o Ombudsman para Assuntos Militares. Conseqüentemente, a partir de 1915 a Suécia passou a ter dois Ombudsmen parlamentares.

Após a Segunda Guerra Mundial, os acontecimentos fizeram com que o Ombudsman para Assuntos Militares fosse cada vez menos sobrecarregado de trabalho, ocorrendo o inverso com o Ombuds. man da Justiça. Em 1968, os dois cargos foram unidos. O Parlamento elegeu três Ombudsmen, cada qual intitulado Ombudsmen da Justiça, mas formando uma única instituição. As tarefas de supervisão foram distribuídas, de acordo com sua natureza, entre eles.

Após 1968, a carga de trabalho dos Ombudsman passou a crescer gradualmente. Tornou-se necessário reorganizar o cargo. Outrossim, uma emenda ao Código Penal, em vigor a partir de 1. de janeiro de 1976, impôs a implantação de novas normas para a supervisão dos $\mathrm{Om}$ budsmen. Assim, em novembro de 1975 , o Parlamento forneceu uma nova instrução aos Ombudsmen parlamentares, contendo novas regras para a organização do seu cargo, bem como para suas tarefas e direitos. Essas normas foram modificadas, parcialmente, em 1986.

\section{A organização atual}

Os Ombudsmen parlamentares são em número de quatro, todos denominados Ombudsmen da Justiça. Um deles é o chefe da equipe. Este é responsável pela administração interna, aponta membros da equipe etc. Traça também as principais orientações das atividades dentro da função. 
Todos os quatro Ombudsmen têm esferas distintas de responsabilidade. Algumas das áreas mais importantes dentro dessas esferas são as seguintes:

Taxação, coleta de impostos e execução de processos, os tribunais comuns, os promotores públicos, a policia e as prisões, as forças armadas, autoridades governamentais locais e as Cortes de Justiça, o bem-estar social e a educação.

Os Ombudsmen são assistidos por uma equipe de aproximadamente 50 pessoas (atualmente 25 advogados, além de escrivãos, datilógrafos, oficiais de justiça, etc.) Somente um Ombudsman, todavia, pode assinar uma decisão final.

Os Ombudsmen são eleitos pelo Parlamento em sessão plenária para um mandato de quatro anos. As eleições são preparadas pela Delegação para os Ombudsmen parlamentares. Tradicionalmente, o Ombudsman deve ser aceito por todos os partidos e eles vêm sendo eleitos por aclamação desde 1971, quando foi introduzido o sistema de uma só câmara (anteriormente as nomeações eram feitas por 48 eleitores, 24 de cada uma das duas câmaras do Parlamento. As reeleiçōes são possiveis e bastante freqüentes.

Não há nenhuma regra que impeça ao Ombudsman ser um membro do Parlamento. Contudo, isso não ocorre há muito tempo. No passado, exigia-se que o Ombudsman tivesse formação na área de $\mathrm{Di}$ reito e, de fato, a maioria deles se originou do setor Judiciário. Desde 1974, não se impõe qualificações especiais para o cargo.

\section{Direitos e deveres}

A supervisão do Ombudsman abrange todos os órgãos federais e municipais, bem como seus funcionários. Quanto às Forças Armadas, entretanto, a supervisão se aplica somente a oficiais de patente superior à de segundo tenente ou equivalente. O Ombudsman também supervisiona todos aqueles que exercem o poder público. Tal poder é, às vezes, exercido por empresas estatais que não são consideradas órgãos ou autarquias governamentais, como por exemplo, uma empresa responsável pelo sistema de segurança do transporte rodoviário. No exercício do poder público (por exemplo, ao proibir que um cidadào dirija um carro defeituoso), a empresa e seus empregados estão sujeitos à supervisão do Ombudsman.

Existem algumas exceçōes às regras acima mencionadas. O Ombudsman não fiscaliza membros do Gabinete, nem membros do Parlamento ou de conselhos municipais. Outras exceções existem, a saber, quanto ao Chanceler da Justiça, bem como à Junta de Governadores ou ao Banco da Suécia (salvo quando se trata de aplicação da legislação sobre câmbio).

Dispositivo expresso das normas que regulam a competência do Ombudsman estabelece que este não deve agir contra funcionários subalternos que não disponham de poderes especiais. Está, também, dito que o Ombudsman, na fiscalização de autoridades municipais, atentará para "os termos em que a autonomia municipal é exercida". Estas observaçōes se referem ao fato de que muitas questōes municipais são tratadas por juntas compostas por leigos, que carecem da experiên-

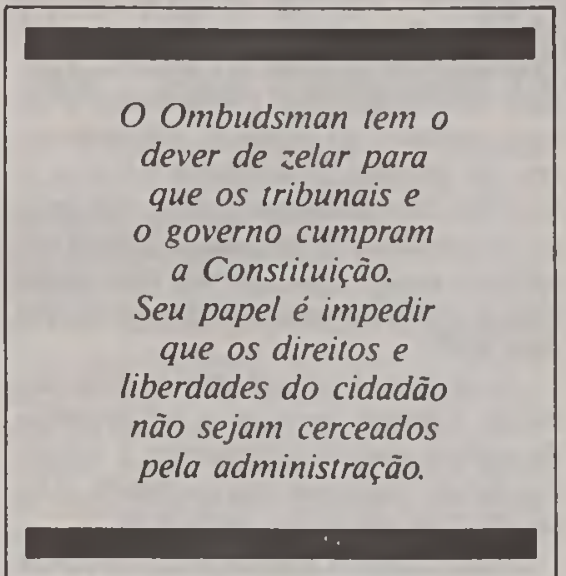

cia e das informações de que dispõem os funcionários públicos. A recomendação deve ser, portanto, entendida como uma sugestão de tolerância no julgamento dessas juntas.

O objetivo da supervisão é assegurar que as autoridades e seus funcionários cumpram devidamente suas obrigaçōes. É dever especifico do Ombudsman zelar para que os tribunais e as autoridades administrativas observem as disposiçōes da Constituição relativas à objetividade e imparcialidade e que os direitos fundamentais e liberdades do cidadão não sejam cerceados pela administração pública.

O Ombudsman pode estar presente nas deliberaçōes de um tribunal ou de uma repartição administrativa, embora sem o direito de pronunciamento. Ele tem acesso a qualquer arquivo ou documento oficial. Todos os funcionários são obrigados por lei a prestar ao Ombudsman qualquer informação que este solicitar e a auxiliá-lo nas investigações. Nenhum documento pode ser tão secreto a ponto de ser ocultado do Ombudsman e nenhum funcionário tem autonomia para recusar-se a responder às perguntas ou, ainda, negar a prestar-lhe assistência durante uma investigação.

Originalmente, a função do Ombudsman era essencialmente a de um promotor especial. Quando um funcionário não cumprisse o seu dever, o Ombudsman poderia aplicar-lhe uma penalidade legal ou, em casos de menor importância, solicitar procedimentos disciplinares. No século XIX, numerosas instauraçōes de processo foram instituidas pelo Ombudsman, mas elas tornaram-se cada vez menos freqüientes. Muitas vezes o Ombudsman não instaurava processos ou instituia medidas disciplinares, mas sim aplicava ao funcionário faltoso uma repreensão. Como tais criticas eram relatadas pela imprensa è impressas no Relatório Anual do Ombudsman para o Parlamento, o qual tem grande penetração junto ao público, elas provocavam um impacto relativamente forte.

Uma emenda ao Código Penal, em vigor desde $1^{\circ}$. de janeiro de 1976 , reduziu a possibilidade de infligir uma punição a um funcionário. Obviamente que crimes tais como apropriação indébita, suborno ou a revelação de um segredo de Estado ainda são punidos. Mas falhas tais como a violação do dever ou a negligência ao cumprimento do trabalho somente são puniveis se a falha for intencional ou devida à negligência grave e cometida no exercicio do poder público. Em muitos dos casos levados até o Ombudsman, as instauraçōes de processo, portanto, já não se justificam. O Ombudsman ainda está autorizado a instituir instaurações de processo, mas entende-se que esse não será o caminho normal para se concluir um caso. O Parlamento, posteriormente, solicitou ao Governo que apresentasse um projeto de lei, emendando o Código Penal de maneira a ampliar novamente a responsabilidade criminal por atos cometidos no serviço civil e militar. Esse projeto de lei será provavelmente apresentado este ano.

As armas mais utilizadas do arsenal do Ombudsman ainda são o poder de repreender ou criticar funcionários faltosos. Se o Ombudsman considerar uma medida inadequada, imprópria ou desaconselhável mas não necessariamente ilegal, ele indicará também como o assunto deverá ser conduzido. Ele poderá ainda recomendar que a questão seja reencaminhada desta ou daquela maneira. Poderá solicitar à autoridade competente que aperfeiçoe as instruções a seus funcionários ou que elabore melhores cronogramas ou formulários. Poderá, outrossim, dirigir-se ao Governo recomendando, por exemplo, 


\section{IDÉIAS}

uma emenda à legislação pertinente. Vale ressaltar que o Ombudsman não pode, ele próprio, anular ou corrigir uma decisão nem pode determinar a um funcionário que tome qualquer iniciativa.

O Ombudsman também fiscaliza as Cortes de Justiça. A principal preocupação do Ombudsman, no particular, é assegurar que os casos sejam julgados e as sentenças pronunciadas dentro de prazos razoáveis. Erros processuais, sobretudo nas instâncias inferiores, poderão às vezes provocar a intervenção do Ombudsman. Antigamente, o Ombudsman era muitas vezes levado a intervir quando partes ou testemunhas recebiam tratamento indevido nos tribunais. Hoje estes casos são raros. As sentenças não estão, no entanto, isentas de fiscalização. O Ombudsman normalmente intervirá quando um erro evidente houver sido cometido. Um exemplo: há alguns anos, uma emenda ao Código Penal entrou em vigor com o propósito de que um tribunal deduzisse, da sentença de punição do transgressor, o período em que este passou preso. Essa emenda não recebeu a devida atenção dos tribunais em muitos casos e as deduções não eram feitas. Após a intervenção do Ombudsman, alguns transgressores (que tinham penas longas a cumprir) tiveram direito a um novo julgamento. Em outros casos, o transgressor foi perdoado e solto no dia em que o seria se a emenda tivesse sido observada. Finalmente, alguns transgressores já haviam cumprido a sentença na sua totalidade e receberam indenização.

\section{Denúncias}

Qualquer pessoa que seja cidadão de outro pais ou não residente na Suécia pode fazer uma denúncia ao Ombuds. man. Nenhuma regra estabelece que o pleiteante deva estar pessoalmente envolvido na questão. Não há limite de tempo determinado, mas admite-se que o Ombudsman não deve, exceto em casos especiais, dar início a uma investigação se a causa da queixa ocorreu há mais de dois anos antes da sua reclamação. Igualmente, nada afirma que todos os recursos judiciais ou administrativos existentes devam ser esgotados antes que uma denúncia seja apresentada. Normalmente, todavia, o Ombudsman não intervém enquanto a matéria estiver pendente no tribunal. Uma intervenção será feita nesse estágio mormente quando a denúncia refere-se ao procedimento, por exemplo, se for alegado que o caso está estagnado ou que a sentença não foi proferida dentro de um periodo razoável de tempo após a audiência. Na maioria dos outros casos, o Ombudsman adiará sua investigação até que a sentença final tenha sido pronunciada ou suspenderá a queixa, deixando que o pleiteante reapresente sua denúncia se ainda estiver insatisfeito após o julgamento final.

A maior parte das decisões das autoridades administrativas suecas ou das Cortes de Justiça estão sujeitas à apelação. O protesto contra as decisões de uma autoridade administrativa pode ser apresentado a outra autoridade administrativa de maior instância ou, em muitos casos, a uma Corte administrativa. Contra as decisões e sentenças da Corte, a apelação só pode ser feita a uma Corte superior. Enquanto a apelação é possível, a atitude do Ombudsman é semelhante à do caso pendente no tribunal. Algumas vezes, no entanto, a denúncia refere-se a questões de pouca importância, com pouca probabilidade de ser tratada junto à autoridade onde a aplicação foi feita; neste caso, o Ombudsman intervirá se sentir que deve fazê-lo.

As queixas devem ser apresentadas por escrito (quando necessário, um membro da equipe ajudará o pleiteante a redigir sua carta). Nenhuma taxa é cobrada. Não se admitem denúncias anônimas.

Nos primeiros 100 anos de existência do cargo, o Ombudsman recebeu cerca de 70 queixas ao ano. A partir de entāo o número cresceu 50 vezes; e, atualmente, o número médio é de 3.500 .

O resultado das queixas tem sido, em média, o seguinte:

Recusadas por estarem fora de jurisdição ou serem de sentido obscuro

Recusadas, por outros motivos, sem investigação

Da competência de outras agências

Nenhuma crítica após a investigação

Repreensōes, recomendaçōes etc.

Instauraçōes de processar ou procedimentos disciplinares Propostas ao Governo

Há que se observar que, em média, somente cerca de $14 \%$ de todos os casos dão origem a algum tipo de providência por parte do Ombudsman (sem contar os casos de competência de outras agências).
Não menos de aproximadamente $40 \%$ são até mesmo recusados sem uma investigação minuciosa, conquanto formalmente não escapem da jurisdição do Ombudsman. Isto pode ser explicado pela rara ocorrência de casos em que os direitos ou a liberdade de um individuo estão realmente em risco. A maioria das denúncias trata de erros de pouca gravidade. Um grande número de queixas não são justificadas. A razão do número de causas levado ao Ombudsman ser relativamente pequeno deve-se ao fato de que tais matérias são normalmente resolvidas de alguma outra forma, por exemplo, através dos promotores comuns.

O número cada yez maior de queixas fez com que o Ombudsman deixasse de admitir de imediato, não só aquelas obviamente infundadas, como também outras de pequena importância. É importante ressalvar, não obstante, que, em muitos dos casos, os arquivos são recolhidos e examinados pela equipe do Ombudsman. Conversações telefônicas entre essá equipe e a agência envolvida são também bastante freqüentes. Desde 1968 o Ombudsman está autorizado a recorrer a outras autoridades ou agências, por exemplo, aos promotores públicos, para os casos que não podem ser recusados, muito embora, não pareçam ser suficientemente sérios, a ponto de justificar sua atenção pessoal.

Todos os outros casos são investigados pelo próprio Ombudsman. O primeiro passo numa investigação é, em geral, a requisição à autoridade interessada dos documentos pertinentes. Em muitos casos, o exame destes documentos é suficiente para saber se a denúncia tem ou não fundamento. O próximo (às vezes o primeiro) passo é solicitar um esclarecimento escrito da autoridade envolvida. Se necessário, correspondência adicional poderá ser trocada e poderão ser pedidos pare38 ceres de peritos ou de órgãos interessados. Em alguns casos, os depoimentos pode-

2 rão ser verbais, em vez de escritos, e podem servir para a obtenção de provas adicionais ou de maior validade. Em certos casos, estes depoimentos são tomados pelo próprio Ombudsman. Normalmente, o Ombudsman delega a um funcionário a investigação. Pode até determinar que a polícia investigue o assunto. Em outros casos, depoimentos orais podem ser substituidos por conversas telefônicas.

Concluída a investigação, o Ombudsman toma uma decisão, a qual, como a maioria dos documentos do escritório do Ombudsman (inclusive as reclamaçōes ou 


\section{IDÉIAS}

denúncias) é pública e divulgada pelos jornais e outros meios de comunicação. Tais decisões, por serem de interesse do Parlamento, de juízes, funcionários públicos etc., são posteriormente publicadas no Relatório Anual do Ombudsman.

Os pleiteantes advêm de todas as camadas da população. Os próprios membros do Parlamento, algumas vezes, embora isto nào seja freqüente, trazem problemas - geralmente envolvendo terceiros - à atenção do Ombudsman. Alunos de faculdade apresentam queixas. Idem professores e alunos de outros níveis. Oficiais do exército reclamam das patentes superiores. O mesmo fazem os seus subalternos. Prisioneiros mostram-se insatisfeitos com as condições das prisōes. Pacientes de hospitais psiquiátricos querem ser transferidos para outros hospitais. Contribuintes estão desgostosos com a maneira pela qual são tratados pelas autoridades.

\section{Investigações iniciadas pelo Ombudsman}

Muitas investigações têm início por própria iniciativa do Ombudsman. A maioria delas baseia-se em observaçōes feitas durante as inspeções. Um relatório dessas inspeções é apresentado posteriormente. Em grande número de casos, relatos jornalisticos das atividades dos tribunais ou de órgãos administrativos deram ao Ombudsman razão suficiente para iniciar uma investigação. O mesmo já aconteceu com programas de televisão. Assim, ao investigar um caso de denúncia, o Ombudsman descobre por vezes situaçōes insatisfatórias ou erros cometidos não abrangidos na denúncia. Ele agirá então por iniciativa própria e procederá a uma nova investigação. Algumas vezes, uma carta anônima, que não é admissível como denúncia, pode provocar a intervenção do Ombudsman, formalmente por iniciativa própria.

Os métodos empregados nos casos iniciados pelo Ombudsman são praticamente os mesmos daqueles utilizados no caso de queixas. Visto que o Ombudsman não inicia uma investigação sem que haja bons motivos, é compreensivel que uma porcentagem muito maior desses casos resulte em algum tipo de medida em relacão às outras queixas.

\section{Inspeções}

Desde que o cargo foi criado em 1810 , o Ombudsman realiza inspeções periódicas em tribunais, prisões, juntas adminis-

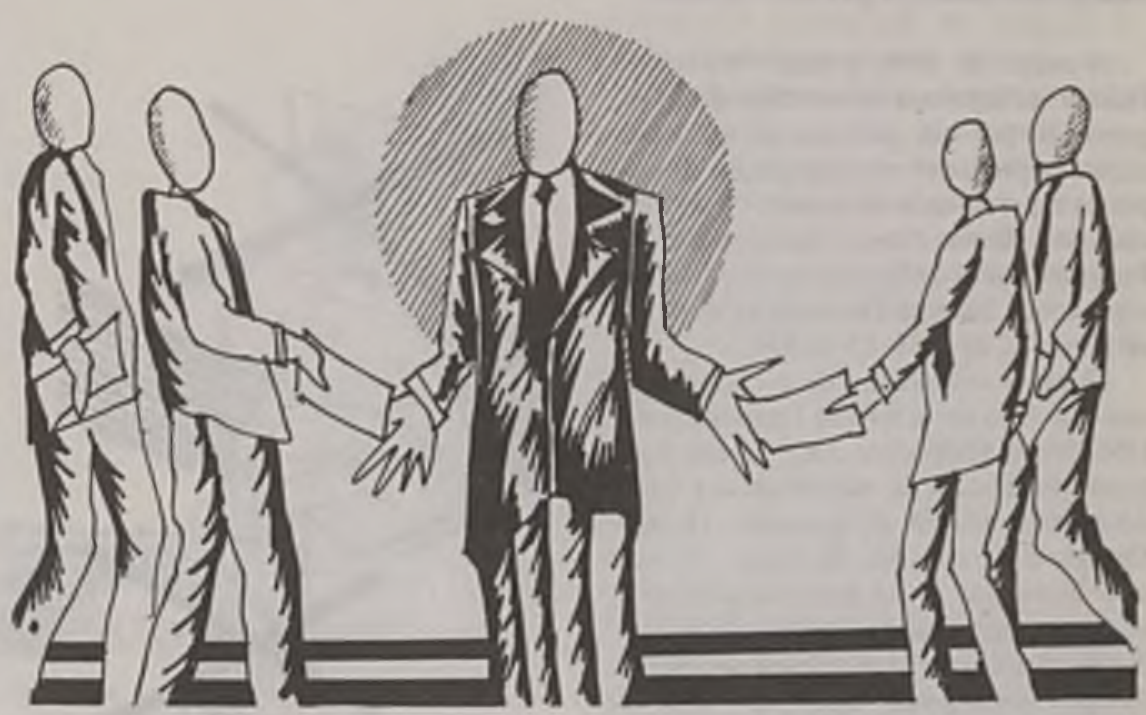

trativas eic. por todo o pais. Da mesma maneira, o Ombudsman para Assuntos Militares, que existiu de 1915 a 1968, supervisionava autoridades militares, regimentos, etc. Quando, em 1968, os cargos de Ombudsman da Justiça e de Ombudsman para Assuntos Militares foram unidos, as inspeçōes tornaram-se mais amplas do que antes. Cada Ombudsman costumava passar 30 dias úteis ao ano fazendo inspeções. Estas também eram feitas por membros da sua equipe em seu nome. As inspeções cobriam agências do governo central, bem como juntas regionais e locais, escritórios e estabelecimentos por todo o país. Da mesma forma, tribunais, órgãos militares, prisōes, hospitais psiquiátricos e estabelecimentos similares eram examinados.

Ao adotar a reforma do cargo do Ombudsman que se efetivou em 1976, o Parlamento julgou ser necessário reduzir o número das inspeções de rotina do Ombudsman. Ele agora passa 20 ou 25 dias ao ano inspecionando.

Durante as vistorias, a maior parte do tempo é gasta no exame de arquivos e documentos. Fazem-se entrevistas com o chefe da junta, escritório ou estabelecimento. Alguns dos outros funcionários também são normalmente entrevistados. Quando uma prisão, um hospital psiquiátrico ou estabelecimento semelhante é vistoriado, os ocupantes têm a oportunidade de falar com o Ombudsman e de expressar as queixas que porventura tenha.

Uma inspeção pode revelar erros em casos individuais, que serão subseqüentemente retificados. Mas freqüentemente, contudo, o Ombudsman pode achar conveniente recomendar que a autoridade in- teressada oriente melhor as instruções dadas aos seus funcionários ou forneça outros formulários, etc. As observaçōes coIhidas durante uma investigação freqüentemente levam o Ombudsman a tomar providências no sentido de remediar deificiências existentes na legislação. $\mathrm{O}$ impacto das inspeçòes é, assim, considerável e de grande benefício para o público em geral.

\section{Relatórios anuais}

Conforme as instruções aprovadas em 1986 pelo Parlamento, o Ombudsman deve apresentar um relatório escrito ao Parlamento até o dia 15 de outubro de cada ano, cobrindo o ano fiscal anterior ( 1 : de julho - 30 de junho). O Relatório Anual, que anteriormente referia-se ao ano civil, contém usualmente em torno de 500 páginas e consiste num relato minucioso de todos os casos de interesse geral tratados pelo Ombudsman. Inclui, desde 1969, um sumário em inglês.

O Relatório é estudado pelo Comitê do Parlamento na Constituição. Este examina também as decisōes do Ombudsman, bem como as minutas e outros documentos. O Comitê então reporta-se ao Parlamento, geralmente acrescentando que não vê motivo de crítica na maneira pela qual - Ombudsman conduziu o seu trabalho. O relatório do Comitê é discutido numa sessão de plenário do Parlamento.

O Relatório Anual também é lido por juizes, funcionários públicos, professores de Direito, etc. É considerado de grande interesse e é freqüentemente mencionado em documentos legais. 